\title{
MODELING SHORELINE RESPONSE AND INLET SHOAL VOLUME DEVELOPMENT ON LONG ISLAND COAST, UNITED STATES
}

\author{
Le Xuan Hoan ${ }^{1,2}$, Hans Hanson ${ }^{1}$, Magnus Larson ${ }^{1}$, Pham Thanh Nam ${ }^{1,2}$
}

\begin{abstract}
A new numerical model was developed to simulate regional sediment transport, shoreline response in the vicinity of tidal inlets, and inlet shoal volume growth based on the one-line model of shoreline change combined with the reservoir concept for volumetric evolution of inlet shoals. Sand bypassing onshore and sheltering effects on wave action from the inlet bar and shoals were taken into account. The model was applied to unique field data from the south coast of Long Island, United States, including inlet opening and closure. The simulation area extended from Montauk Point to Fire Island inlet, including Shinnecock and Moriches Inlets (Figure 1). A 20-year time series of hindcast wave data at three stations along the coast were used as input data to the model. Several types of sediment sources and sinks were represented, including beach fills, groin systems, jetty blocking, inlet bypassing, and flood shoal and ebb shoal feeding. The model simulations were validated against annual net longshore transport rates reported in the literature, measured shorelines, and recorded sediment volumes in the flood and ebb shoal complexes. Overall, the model simulations were in good agreement with the measured data.
\end{abstract}

Keywords: shoreline modeling; inlet model; shoreline response; flood shoal; ebb shoal; sand bypassing

\section{INTRODUCTION}

Morphology change and shoreline response in the vicinity of tidal inlets are controlled by both dynamic and static factors. Dynamic factors include net longshore transport, tidal prism, and wave regime, whereas properties of structures, angle of ebb jet related to the local shoreline, general offshore and nearshore bathymetry, size and shape of the back bay, sediment grain size, and artificial beach fills are static factors (Carr and Kraus, 2001). The dynamic factors can play a role in regional coastal processes, whereas the static factors often act at the scale of the local processes. Engineering activities around tidal inlets, such as creation and maintenance of navigation channels, require comprehensive knowledge of regional and local processes as well as the interactions between them. Regional sediment transport and shoreline evolution models that include local processes at tidal inlets are to a large degree lacking at present.

Kraus $(2000,2002)$ introduced a mathematical aggregate model of volume change and sand bypassing at tidal inlets, based on a reservoir analogy approach. In this model, the ebb shoal, bypassing bar, and attachment bar were included, but the flood shoal and main channel were neglected. Larson et al. (2002a) introduced a numerical model to simulate sediment transport and coastal evolution at regional scale, named Cascade. This model can simultaneously simulate different spatial and temporal processes at scales from regional to local. Regional sediment transport and shoreline change extending hundreds of kilometers and covering several inlets were represented. The model also includes inlet phenomena such as inlet creation, ebb shoal development, and bypassing bars between beaches and inlets. Larson et al. (2006) further developed the inlet reservoir model to include flood shoal development, based on the model introduced by Kraus (2002). This model was then included in Cascade after which the sediment transport and shoreline response in the vicinity of Shinnecock Inlet and Moriches Inlet on the south coast of Long Island, United States, were simulated. However, in these simulations the shoreline change downdrift the inlets were not well reproduced. The reasons for this discrepancy between calculations and measurements are attributed to sand moving onshore from the attachment bars, as well as the sheltering effects on wave action from the inlet shoals and bars. These processes have not been included in any previous model. Thus, in order to develop a general model for regional coastal evolution with regard to the effects of inlets, sand bypassing onshore from the attachment bars and the sheltering effects of the inlet morphological elements on the downdrift shoreline were described in the present model.

\footnotetext{
${ }^{1}$ Dep. of Water Resources Engineering, Lund University, Box 118, Lund, S-22100, Sweden

2 Institute of Mechanics, VAST, 264 Doi Can, Hanoi, 10000, Vietnam
} 
In this study, a new numerical model of regional sediment transport and shoreline change, combined with the inlet reservoir model, is introduced. The shoreline change model was based on oneline theory following basic formulations and algorithms developed by Hanson (1987). The predictive formula for longshore transport rate as modified by Larson et al. (2002a) to include shoreline characteristics at the regional scale was employed. Measured data by Gaudiano and Kana (2001) were used to model the onshore movement of a portion of the attachment bar volumes. Sheltering effects on the wave action from the inlet shoals and bars were represented by an attenuation coefficient affecting the breaking wave height in the sheltered area. Distances from the centerline of the inlets to the attachment bars were calculated using the empirical formulas introduced by Carr and Kraus (2001). The model was employed to simulate the coastal evolution of the Long Island coast covering the inlets at Shinnecock and Moriches. Measured shorelines in 1983, net longshore transport rates estimated by Rosati et al. (1999), and measured volumes of the flood and ebb shoal complexes (the ebb shoal complex includes ebb shoal, bypassing bar, and attachment bar) were used to validate the model.

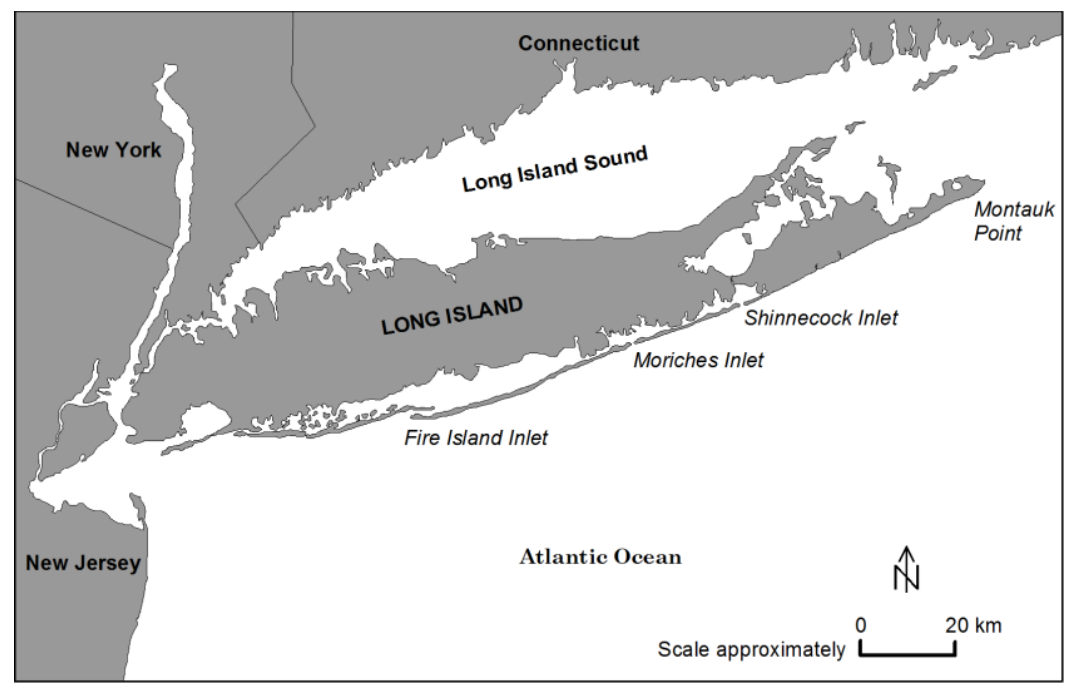

Figure 1. Study site and the locations of Shinnecock and Moriches Inlets on the south Long Island coast, New York.

\section{METHODOLOGY}

The model development focused on simulating regional sediment transport and local shoreline response in vicinities of the tidal inlet as well as development of the tidal shoal volumes. Regional sediment transport and shoreline evolution was simulated based on the shoreline change model developed by Hanson (1987). The inlet reservoir model based on a reservoir analogy approach developed by Kraus (2000, 2002) was employed.

\section{Shoreline change model}

The shoreline change modeling is based on the one-line theory (Pelnard-Considere, 1956), employing algorithms for the numerical solution developed by Hanson (1987). Conservation of sediment volume yields the fundamental equation to be solved for obtaining the shoreline change. Employing a local coordinate system, where the $y$-axis points offshore and the $x$-axis is oriented parallel to the trend of the shoreline, this equation is expressed as,

$$
\frac{\partial y}{\partial t}+\frac{1}{\left(D_{B}+D_{c}\right)}\left[\frac{\partial Q}{\partial x}+q\right]=0
$$

where: $x=$ longshore coordinate; $y=$ cross-shore shoreline position; $t=$ time; $D_{B}=$ average berm elevation; $D_{c}=$ depth of closure; $Q=$ longshore sand transport rate; $q=$ source or sink of sand.

The empirical predictive formula for the total longshore sand transport developed by Hanson et al. (2006) was used,

$$
Q=\frac{\varepsilon}{8\left(\rho_{s} / \rho-1\right)(1-p) w_{s}} H_{b}^{2} C_{g b} \cos \alpha_{0}\left[K_{1}\left(a_{1} \sin \alpha_{0}+\bar{V}_{e}\right)-K_{2} a_{2}\right]
$$


in which, $a_{1}=\frac{5}{32} \frac{\pi \lambda}{C_{f}} \sqrt{g} A^{\frac{3}{2}} ; a_{2}=\frac{\pi}{C_{f} \lambda^{2}} \sqrt{g h_{b}} \frac{\partial H_{b}}{\partial x}$ and $A=2.25\left(\frac{w_{s}^{2}}{g}\right)^{\frac{1}{3}}$

where: $H=$ wave height; $h=$ water depth; $C_{g}=$ wave group celerity; $b=$ subscript denoting breaking wave condition; $K_{l}, K_{2}=$ empirical coefficients (treated as calibration parameters); $\rho_{s}=$ density of sand; $\rho=$ density of water; $p=$ porosity of sand on the bed; $w_{s}=$ fall velocity; $\overline{V_{e}}=$ external surfzone average longshore current velocity generated by tide or/and wind; $A=$ shape parameter; $\lambda=$ breaker index; $g=$ acceleration due to gravity; $C_{f}=$ bottom friction coefficient; $\varepsilon=$ transport coefficient expressing efficiency of the waves keeping sand grains in suspension, which can be estimated through physical parameters as (Bayram et al., 2007), $\varepsilon=\left(4.0+9.0 \frac{H_{b}}{w_{s} T}\right) \times 10^{-5} ; \alpha_{0}=$ angle of breaking waves to the local shoreline orientation given by,

$$
\alpha_{0}=\alpha_{b}-\arctan (\partial y / \partial x)
$$

The effect of a regional shoreline shape enters in Eq. (3) by assuming that the local shoreline evolves with respect to the regional shoreline (Larson et al., 2002a), yielding a new expression for $\alpha_{0}$,

$$
\alpha_{0}=\alpha_{b r}+\alpha_{b}-\arctan (\partial y / \partial x)
$$

where $\alpha_{b r}=\arctan \left(\partial y_{r} / \partial x\right)$ and $y_{r}$ denotes the regional shoreline, which is taken to be constant in time.

\section{Inlet Reservoir Model}

Larson et al. (2006) refined the inlet reservoir model by Kraus (2002) through the introduction of the flood shoal and associated coupling coefficients, which analytically describe the transfer of sediment between the morphological units. The inlet morphology is schematically divided into distinct morphology units including ebb shoal, bypassing bars, attachment bars, and flood shoal (Figure 2). Each morphological unit is assumed to have a certain equilibrium volume for fixed hydrodynamic and sediment conditions.

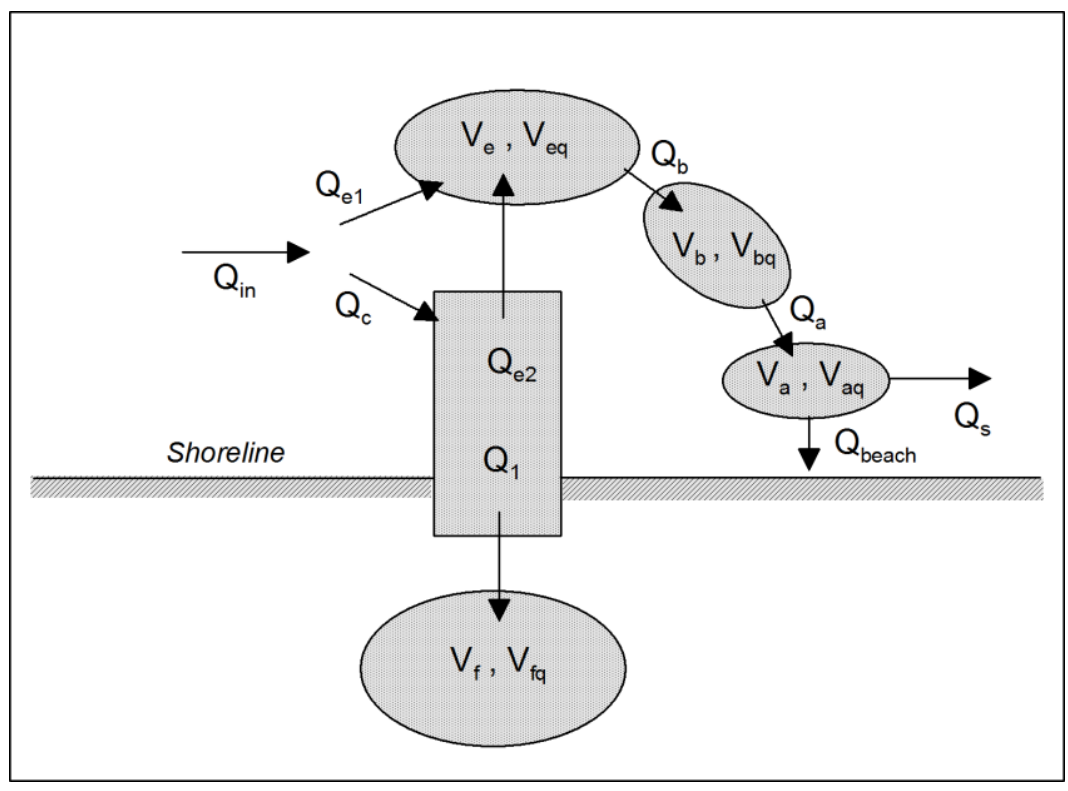

Figure 2. Definition sketch for inlet morphological units with sediment transport occurring from the right-hand side (after Larson et al., 2002a). 
In order explain the inlet model employed in the present study, the simple case of sediment being transported from left-to-right is considered here, where $Q_{i n}$ is the incoming sediment transport rate around the jetty (if such a structure is present). The transport $Q_{i n}$ is split into one portion that goes to the ebb shoal, $Q_{e 1}$, and one portion that goes into the channel, $Q_{c}$. Once in the channel, the sediment might be transported to the ebb shoal, $Q_{e 2}$ or to the flood shoal, $Q_{f}$. Sediment at a rate $Q_{b}$ is leaving the ebb shoal and feeding the bypassing bar. The volume of the ebb and flood shoal at any given time is $V_{e}$ and $V_{f}$, respectively, with the corresponding equilibrium values of $V_{e q}$ and $V_{f q}$.

The mass conservation equation of sediment for the ebb shoal is,

$$
\frac{d V_{e}}{d t}=Q_{e 1}+Q_{e 2}-Q_{b}
$$

and for the flood shoal,

$$
\frac{d V_{f}}{d t}=Q_{f}
$$

Transport out of the ebb shoal is,

$$
Q_{b}=\frac{V_{e}}{V_{e q}}\left(Q_{e 1}+Q_{e 2}\right)
$$

Transport rates between elements are defined through the coupling coefficients,

$$
\begin{gathered}
Q_{e 1}=\delta Q_{i n} ; Q_{c}=(1-\delta) Q_{i n} \\
Q_{e 2}=\beta(1-\delta) Q_{i n} ; Q_{f}=(1-\beta)(1-\delta) Q_{i n}
\end{gathered}
$$

where $\delta$ and $\beta$ are coupling coefficients defined as follows (Larson et al. 2006),

$$
\delta=\frac{V_{e}+V_{f}}{V_{e q}+V_{f q}}, \beta=\frac{1-V_{e} / V_{e q}}{2-V_{e} / V_{e q}-V_{f} / V_{f q}}
$$

Sediment at rate $Q_{a}$ is leaving the bypassing bar and feeding the attachment bar. The volume of the bypassing and attachment bars at any given time is $V_{b}$ and $V_{a}$, respectively, with the corresponding equilibrium values $V_{b q}$ and $V_{a q}$.

The sediment volume conservation equation for the bypassing bar is,

$$
\frac{d V_{b}}{d t}=Q_{b}-Q_{a}
$$

where the transport from the bypassing bar is given by,

$$
Q_{a}=\frac{V_{b}}{V_{b q}} Q_{b}
$$

The transport out from the attachment bar and further along the shore, $Q_{s}$, is:

$$
Q_{s}=\frac{V_{a}}{V_{a q}} Q_{a}
$$

In the area of the bypassing and attachment bars, incident wave energy greatly exceeds ebbdirected tidal energy, allowing a portion of the ebb shoal to migrate towards the shore under accretionary wave conditions (Kana et al., 1999; Rosati et al., 1999; Gaudiano and Kana, 2001). Thus, shoal bypassing is a natural form of beach nourishment (Gaudiano and Kana, 2001). This process is believed to contribute partly in the generation of a salient-type feature commonly observed on beaches downdrift inlets. In order to describe the process of onshore sand transport from the attachment bar to 
the shoreline in the numerical model, a macroscopic approach is taken where it is assumed that a certain fraction of the transport supplying the attachment bar volume is transferred to the beach at each calculation time step. Thus, sediment moves at a rate $Q_{\text {beach }}$ from the attachment bar to the shoreline, expressed through a fraction, $\gamma$, of the total net sand transport being supplied to the attachment bar at any given time,

$$
Q_{\text {beach }}=\gamma\left(Q_{a}-Q_{s}\right)=\gamma Q_{a}\left(1-\frac{V_{a}}{V_{a q}}\right)
$$

The sediment volume conservation equation for the attachment bar is:

$$
\frac{d V_{a}}{d t}=Q_{a}-Q_{s}-Q_{\text {beach }}=(1-\gamma)\left(Q_{a}-Q_{s}\right)
$$

Larson et al. (2002a) introduced a nonlinear relationship for releasing sediment from the ebb shoals when the inlet cross-sectional area is decreasing or closes completely. Thus, the above equations, (7), (12), (13) and (14) were changed to a nonlinear form, that is, $Q_{\text {out }}=Q_{i n}\left(V / V_{q}\right)^{n}$, where $Q_{\text {out }}$ and $Q_{\text {in }}$ are sediment transport rates going out and entering a morphological unit, respectively, $V$ and $V_{q}$ are the volumes at a given time and at equilibrium of the unit, and $n$ is an empirical power. By specifying a value of $n<1$ for situations where sediment is released back to the beach, the release will be slower than for the linear model. Larson et al. (2002a) suggested a value of $n$ between 0.1 and 0.2 when the shoal experienced reduction in volume.

Distance to attachment bars. According to Hicks and Hume (1996) and Carr and Kraus (2001), the tidal prism is expected to control the size and location of the ebb shoal. Carr and Kraus (2001) developed an empirical relationship between tidal prism and the distance from the centerline of the inlet to the downdrift and updrift attachment bars by examining 108 tidal inlets in the United States. The inlets were classified according to whether the inlets had two, one or no jetties. For inlets with two jetties, the empirical relationships governing distance to the attachment bar was found to be,

$$
\begin{aligned}
& \text { for downdrift attachment bars: } W d=0.50 \times P^{0.451} \\
& \text { for updrift attachment bars: } \quad W u=0.16 \times P^{0.495}
\end{aligned}
$$

where $W d$ and $W u=$ distance from centerline of the inlet to the downdrift and updrift attachment points where the ebb shoal complex attaches to the shoreline (in $\mathrm{m}$ ), respectively.

The angle between the orientation of the ebb jet and the shoreline affects the size and shape of the shoals and bars (Hicks and Hume, 1996); thus, the above relationships could be modified for improved predictability by including the ebb jet angle. If the ebb jet is perpendicular to the local shoreline trend, the morphological asymmetry is mainly controlled by the magnitude and direction of net longshore transport, as well as wave refraction and diffraction over the bathymetry and ebb shoal. Thus, a straight channel is expected to promote morphological symmetry and a reduced distance to the downdrift attachment point (Carr and Kraus, 2001). However, if the ebb jet angle becomes more acute, the tidal and wave energy oppose each other less. An ebb jet flow more parallel to the wave crests implies that the waves can more efficiently return shoreward sand deposited from the ebb jet (Hicks and Hume, 1996), but at a location further downdrift. Thus, a more acute ebb jet angle is expected to promote more sand being transferred to the downdrift beach and a longer distance to the attachment bar. These effects are believed to act at Shinnecock Inlet as well as at Moriches Inlet (Carr and Kraus, 2001), where the ebb shoal is attached to the updrift shoreline close to the jetty with an extended distance to the downdrift attachment bar. Thus, Eqs. (16) and (17) were modified by including the angle between the ebb jet and the local shoreline, $\psi$, expressed as,

$$
\begin{aligned}
& \text { for downdrift attachment bars: } W d=0.50 \times P^{0.451}(1+\cos \psi) \\
& \text { for updrift attachment bars: } \quad W u=0.16 \times P^{0.495}(1-\cos \psi)
\end{aligned}
$$

For the case where the ebb jet is perpendicular to the shoreline, $\psi$ takes on a value of $90 \mathrm{deg}$, implying no asymmetry due to ebb jet orientation. 
Wave sheltering effects from attachment bar. Beach erosion typically occurs along the shoreline on both sides of the attachment bar, whereas accretion occurs in its lee (Dean and Walton, 1975; Williams and Kana, 1987; Gaudiano and Kana, 2001) (see Figures 3 and 4). The sheltered area behind the bar is gradually filled in, and finally the shoal attaches to the shore resulting in alongshore spreading of the bar in both directions from the point of attachment (Gaudiano and Kana, 2001). Thus, there are two mechanisms that cause sediment to gradually feed sand to the area behind the bar. The first mechanism is the onshore bypassing process of sand from the attachment bar due to landward flow associated with the waves (Williams and Kana, 1987; FitzGerald et al. 2000). The second mechanism is due to the sheltering from the wave activity provided by the bar, which produces a zone of low energy in which alongshore currents can deposit transported material (Dean and Walton, 1975). The onshore bypassing process is described through the coefficient, $\gamma$, which represents the fraction of the transport supplied to the attachment bar build-up that is transferred to the shore (see Eq. (14)). The decrease in wave energy in the lee of the bar is expressed through a reduction in breaking wave height. In the numerical model, a calibration parameter for reduction of the breaking wave height in the lee of the bar was introduced. The value of this parameter depends on the size and shape of the bar, which are different on the downdrift and updrift sides of the inlet due to asymmetry in inlet morphology. The breaking wave height in the lee of the bar was multiplied by a spatially varying attenuation parameter, $\eta$, and thus, $H_{b}$ in Eq. (2) was replaced with $\eta H_{b}$, where $0 \leq \eta \leq 1$. The value of $\eta$ is less than 1.0 behind the bars, and equals 1.0 outside the sheltered areas. In principal, $\eta$ has a minimum value at the centre point of the sheltered area, and its value increases towards both sides of the bar. As a simplification for this study, the values of $\eta$ within the sheltered areas were obtained by linearly interpolating between a minimum value at the centre point of the respective sheltered area and 1.0 in areas not sheltered by the bar. The minimum values inside the bars were determined through a calibration procedure.

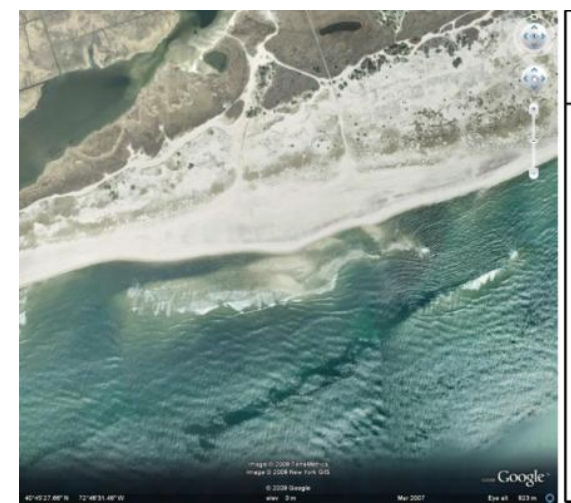

Figure 3. Onshore migration of sediment from attachment bar at Moriches Inlet.

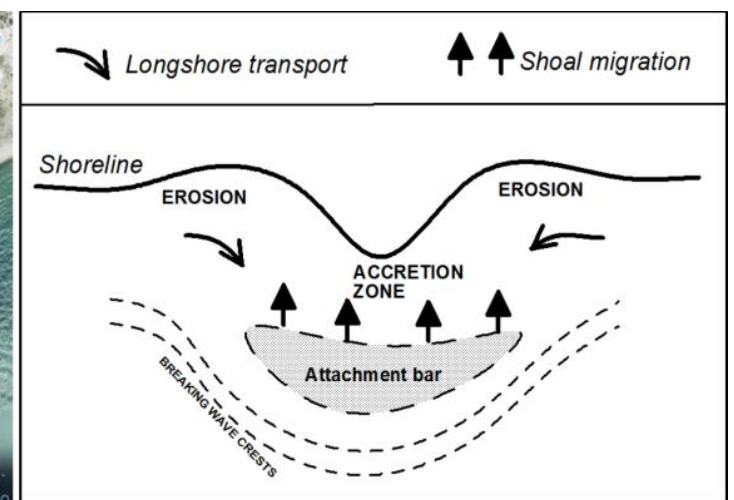

Figure 4. Depiction of sand movement (after Kana et al., 1985).

\section{Study area and model setup}

The south shore of Long Island, New York, was selected as a suitable location for validating the capability of the model to simulate regional sediment transport and development of tidal inlet shoal volumes. The study area extended from Fire Island Inlet to Montauk Point because the most available information originated from this coastal stretch (Larson et al., 2002a). The stretch includes many coastal features and processes such as sediment transport and evolution at regional scale, the crosssectional areas of the inlets varied substantially with time including opening and closure of the inlets, substantial shoreline response in vicinities of the jettied inlets, large amount of beach fill volumes placed at several locations along the coast (Larson et al., 2002a), and a system of groins constructed to protect the beach.

Two types of simulations were performed with the new numerical model for the study area: (1) simulating the overall annual net longshore transport and regional shoreline evolution; and (2) simulating shoreline response in vicinities of the inlets and the tidal inlet shoal development in connection with varying cross-sectional area of the inlets. The objectives of these simulations were to validate the capability of the model to simulate shoreline response in the vicinity of the inlets and tidal 
inlet shoal development at local scale in combination with longshore sediment transport and shoreline evolution at regional scale.

The Long Island shoreline has a length of about $135 \mathrm{~km}$ and it is oriented in a direction of about 67.5 deg northeast. A model coordinate system was defined with a similar orientation of the $x$-axis. The lateral boundary conditions for the modeling consisted of "no shoreline change" specified based on shoreline measurements covering a period from 1830 to 1995 (Larson et al., 2002a). Suitable locations for such a boundary condition were identified approximately $10 \mathrm{~km}$ west of Montauk Point and $15 \mathrm{~km}$ east of Fire Island Inlet.

The inlet reservoir model requires a specification of the equilibrium bar and shoal volumes. Walton and Adams (1976) developed predictive empirical formulas for the equilibrium volume of an ebb tidal shoal depending on the tidal prism and the amount of wave exposure of the coasts classified into groups of highly exposed, moderately exposed, and mildly exposed coasts. The formula for moderately exposed coasts is most applicable to the inlets along the southern shore of Long Island (Millitello and Kraus, 2001), and thus it was used in this study,

$$
V_{E}=6.44 \times 10^{-3} \times P^{1.23}
$$

where $V_{E}=$ volume of ebb shoal complex at equilibrium (in $\mathrm{m}^{3}$ ); and $P=$ spring tidal prism (in $\mathrm{m}^{3}$ ) was estimated based on the relationship between cross-sectional area and tidal prism for the Atlantic Ocean coast and inlets with two jetties as (Jarrett, 1976; Militello and Kraus, 2001),

$$
A_{c}=14.74 \times 10^{-5} P^{0.95}
$$

where $A_{c}=$ minimum cross-sectional area of the entrance channel below mean sea level (in $\mathrm{m}^{2}$ ).

Hindcast wave data (a 20-years time series at an interval of 3 hours from 1976 to 1995) from three WIS Stations along the coast was used as input data for the modeling. The spatial step was set at 100 $\mathrm{m}$, and the input wave parameters were linearly interpolated based on the three stations corresponding to this spatial interval. The time step was set at 3 hours, coinciding with the interval of measured wave data. Following Larson et al. (2002a), the depth of closure was chosen to $8 \mathrm{~m}$ and the representative median grain size $0.3 \mathrm{~mm}$. The regional shoreline shape was determined from spatial filtering of the shoreline measured in 1870 when no inlets existed using a window length of $7 \mathrm{~km}$ (Larson et al. 2002a).

Measurements of inlet cross-sectional areas at Shinnecock and Moriches Inlet were performed at several occasions between 1931 and 1998, which includes the closure and subsequent opening of Moriches Inlet in the 1950's. These data were used to calculate the equilibrium volumes of the ebb shoal complexes, from which the equilibrium volumes of the individual morphological units at the inlets could be estimated (Larson et al., 2002a). Equilibrium volume of the flood shoals were set to $4.10^{6} \mathrm{~m}^{3}$ for both inlets (Larson et al., 2006).

Several structures were included in the simulations. Jetty lengths on each side of the inlets and the time of construction were specified according to information from the literature. The lengths of the east and west jetties at Moriches Inlet are $258 \mathrm{~m}$ and $445 \mathrm{~m}$, respectively, and the jetties were constructed in 1953 (Vogel and Kana, 1984). For Shinnecock Inlet, the lengths of the east and west jetties are $280 \mathrm{~m}$ and $450 \mathrm{~m}$, respectively, with construction carried out in 1953 (Smith et al., 1999). Changes in the jetty lengths were not modeled, but they were kept constant during the simulation time after completion. The 15 groins comprising the Westhampton groin field were constructed in three phases, from March 1965 to October 1966, from 1969 to 1970, and in 1998 (Rosati et al., 1999). These groins were included in the model at the proper times and the lengths and locations of the groins were specified based on available data.

Dredged material has typically been placed along adjacent beaches or within nearshore areas east and west of the inlets (Smith et al., 1999). These beach fill volumes were included in the model as source terms in the sediment conservation equation that vary in time and space. A total volume of about $800,000 \mathrm{~m}^{3}$ was placed west of Shinnecock Inlet between 1949 to 1983 , and another $1,115,000 \mathrm{~m}^{3}$ was put in this area between 1983 and 1995 (Larson et al., 2002a). From 1955 to 1969, a total volume of about $661,000 \mathrm{~m}^{3}$ was placed east of the inlet. Total quantities placed at Moriches Inlet between 1953 to 1996 were approximately 2.5 million cubic meters in which about 1.3 million cubic meters (52\%) and 0.75 million cubic meters $(30 \%)$ were placed to the east and west of the inlet, respectively (Smith et al., 1999). Smaller beach fills have been placed at other locations, but they were neglected in the present modeling study. 
In order to employ Eqs. (18) and (19), the angle between the ebb jet and the local shoreline must be specified. At Shinnecock Inlet, after completion of the jetties, the inlet opening rotated to conform to the jetty orientation which were in a north-south direction (Smith et al., 1999), and at Moriches Inlet, the channel was oriented slightly east of north entering the inlet (Psuty et al., 2005). The ebb jets are generally oriented parallel to the jetties. Based on satellite images, the angle between the ebb jet and local shoreline at Shinnecock and Moriches Inlet were set to $60 \mathrm{deg}$ and $67 \mathrm{deg}$, respectively.

The equilibrium volumes, $V_{e q}, V_{b q}$ and $V_{a q}$, of each morphology unit must be specified in Eqs. (5) to (15). Limited information exists on the equilibrium size of the individual morphological units described in the reservoir model. To simplify, the units are determined as being a constant fraction of the volume of the ebb shoal complex, which in turn is a function of inlet cross-sectional area (tidal prism). Militello and Kraus (2001) estimated sand bypassing to the attachment bar at a rate of about $19,000 \mathrm{~m}^{3} / \mathrm{yr}$ for Shinnecock Inlet. The rate of ebb shoal growth, which is estimated to $117,000 \mathrm{~m}^{3} / \mathrm{yr}$ (Williams et al., 1998), implies that the ratio between the attachment bar and the ebb volume growth is 0.16 . The ratio between bypassing bar and the ebb shoal volume is assumed to be 0.25 following Larson et al. (2002a). In the present study, the same ratios were employed for the both inlets.

To employ Eqs. (14) and (15), the fraction of the transport causing deposition on the attachment bar transferred to the shore at any given time must be specified. Gaudiano and Kana (2001) analyzed nine tidal inlets in South Carolina on the Atlantic Coast, which revealed that only a small fraction of the entire ebb shoal complex are transferred to the shore during bypassing events. The mean volume percentage is about 3.1. Taking into consideration the ratio between the attachment bar and the ebb shoal complex volume, the sand volume percentage transferred to the shore is about 20.0. Thus, the coefficient $\gamma$ in the Eqs. (14) and (15) was set to 0.20 .

The length of the attachment bars must be specified when modeling the alongshore distribution of the onshore sand transport from the attachment bar. This term could be expressed through the distances from inlet to the attachment bars, which is a function of the tidal prism. The assumption is made here that the length of the attachment bar corresponds to half the distance from the inlet to the attachment bar center.

\section{RESULTS AND DISCUSSION}

\section{Shoreline evolution}

The model was first run for the period 1933 to 1983 to compare with the measured shoreline in 1983. The simulated and measured shorelines, as well as the initial shoreline, are plotted in Figure 5. The transport coefficients were chosen based on the best fit between simulated and measured shorelines to be $K_{1}=0.15$ and $K_{2}=0.04$, respectively. The value of the transport coefficient was held constant for the entire study domain. The wave height attenuation coefficient was set to $\eta=0.85$, implying that the breaking wave height at centre point of the lee of the attachment bars decreases $15 \%$ compared to the height outside the sheltered areas. This value was held constant during the entire simulation time, as well as for the downdrift and updrift bars. In general, $\eta$ depends on the size and shape of the attachment bar, the incident wave energy relative to the tidal energy, and the wave refraction and diffraction around the bar. Ebb shoal volumes vary over time and differ between downdrift and updrift sides due to the morphological asymmetry of tidal inlet. However, for long-term simulation performed here, the attenuation coefficient is regarded as an average value.

The simulated shoreline is overall in good agreement with the measured shoreline, particularly on the updrift side of the jetties and in the downdrift area where the salient-type feature appears. However, at Shinnecock Inlet, on both sides of this feature, the shoreline retreat was overestimated by the model, and south of the downdrift attachment bar at Moriches Inlet, the simulated shoreline retreat was underestimated. The reason for this discrepancy may be due to several factors, at regional and local scale, that were not included in the model. Overwash by storm waves could produce shoreward displacement of the shoreline, which may have been the case west of Moriches Inlet. During storm surge, waves may overtop the island, and overwash of sediment occurs. This sediment is deposited on the back of the island and it is lost from the nearshore system or transported back at a low rate by wind (Larson et al., 2002b). Large storm events have contributed to significant alteration of the Fire Island shoreline. These storms generally cause rapid beach erosion, dune displacement, and coastal flooding (Psuty et al., 2005).

A local transport process, not described in the model, is a part of the transport system that is formed when sediment moves around the inlet, being bypassed through the shoals and bars (Kana et al., 
1999). In this system, a portion of the bypassing sand cycles back to the inlet (Williams and Kana, 1987; Kana et al., 1999) due to flood tidal currents and wave refraction around the ebb shoal. This process is expected to produce erosion in the area close to the jetties. In addition, there are a number of other factors expected to cause the difference between the modeled and measured shorelines that were not included the model, such as wind-blown sand, inlet channel dredging, and sea level rise.

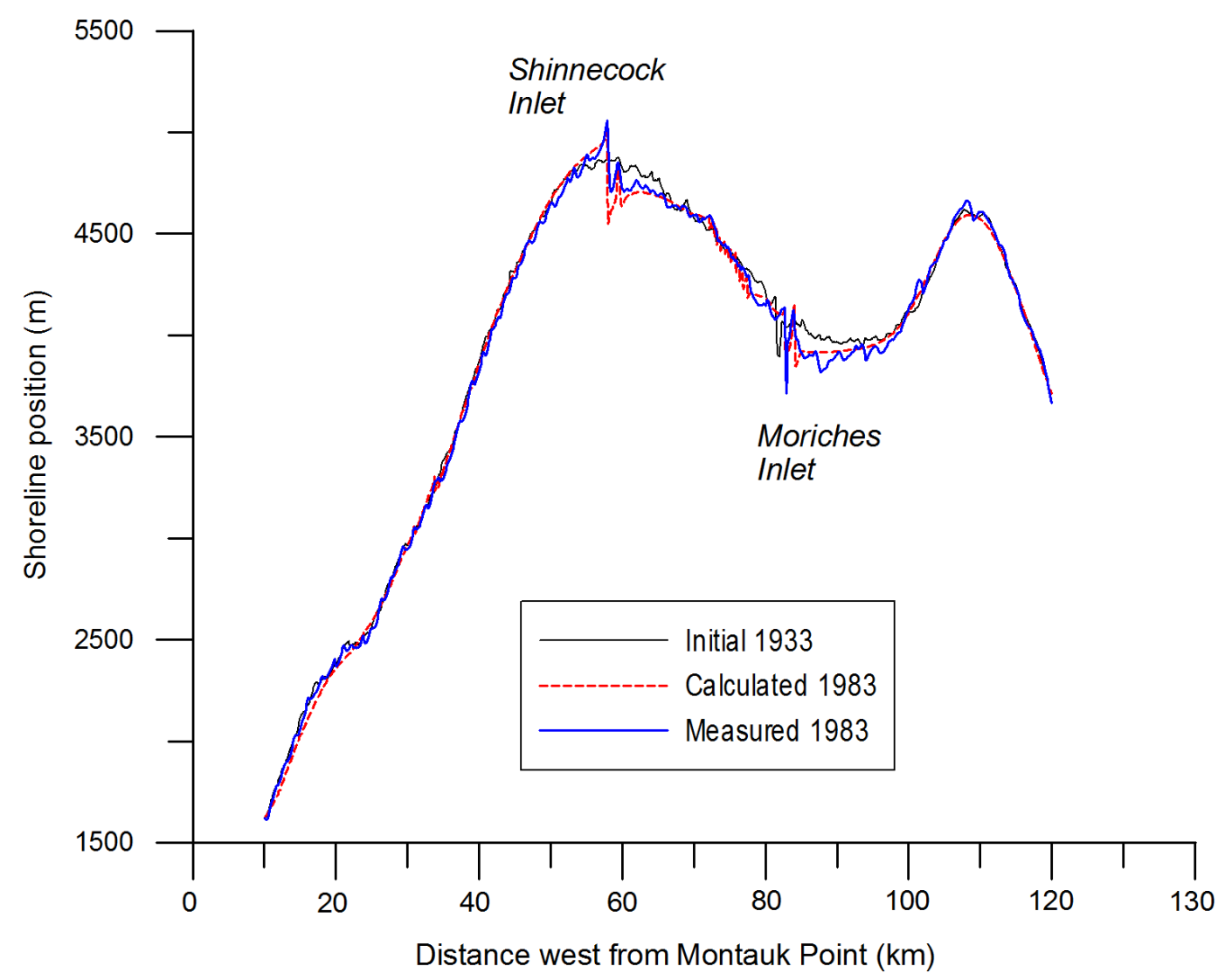

Figure 5. Comparison between the measured and simulated shoreline in 1983.

\section{Longshore transport rate}

The simulated net transport rate together with the derived transport data reported by Rosati et al. (1999) is plotted in Figure 6. The simulated annual net longshore transport rates were in good agreement with the analyzed data, except at Montauk Point where the rate was underestimated. The data from Rosati et al. (1999), for Montauk Point, included several important sinks and sources not described in the model, such as offshore losses due to sea level rise $\left(76,000 \mathrm{~m}^{3} / \mathrm{yr}\right)$, beach fill placement (from zero to $170,000 \mathrm{~m}^{3} / \mathrm{yr}$ ), and bluff erosion (from 33,000 to $203,000 \mathrm{~m}^{3} / \mathrm{yr}$ ). This will affect net transport rates and cause a difference between the modeled and analyzed results at Montauk Point.

The net annual longshore transport rate exhibits an increasing trend from Montauk Point to Fire Island Inlet. Since the tidal inlets act as sinks to the longshore transport as they evolve towards their equilibrium state, the net transport rate decreases significantly across the inlets. The average annual longshore net transport rate obtained in this study is $100,000 \mathrm{~m}^{3} / \mathrm{yr}$.

\section{Flood and ebb shoal growth}

The model was also run for the period 1933 to 2000 to compare with the measurements of ebb and flood shoal volume growth. Comparison between the calculated and measured ebb and flood shoal volumes are plotted in Figures 7 and 8, respectively, where the total volume of the ebb shoal complex is displayed. Overall, the calculated and measured data are in good agreement, although specific individual points show more discrepancy. 


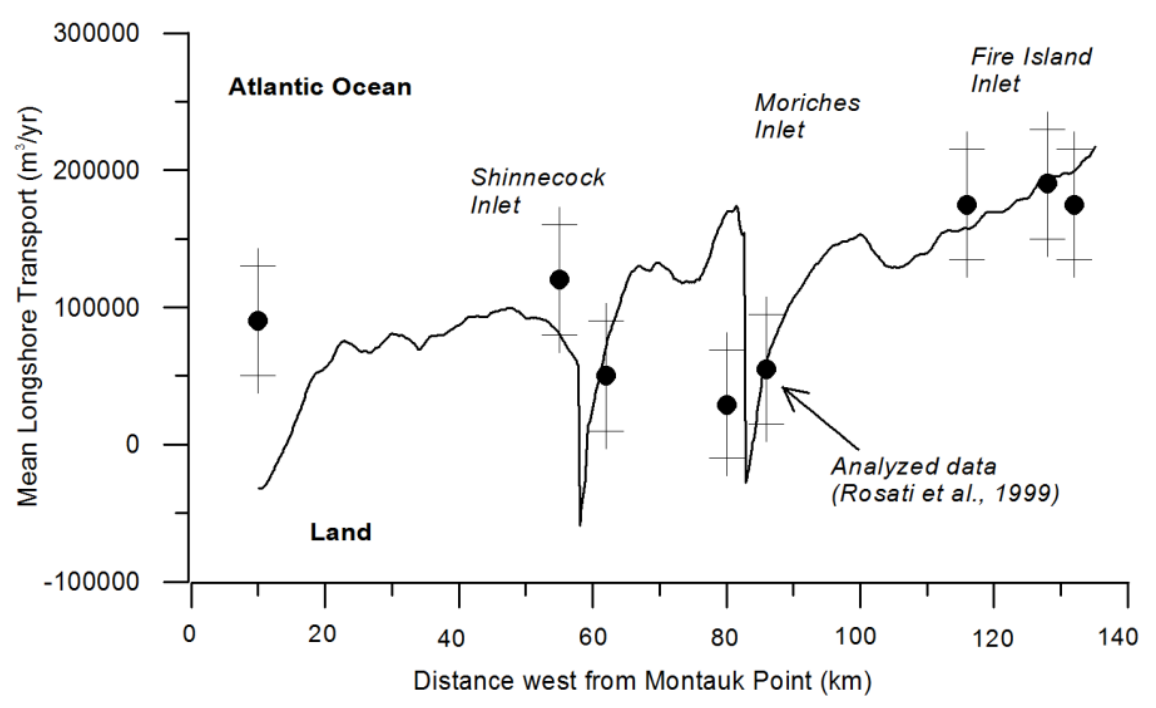

Figure 6. Comparison between annual net transport rate and estimated data from measurements.

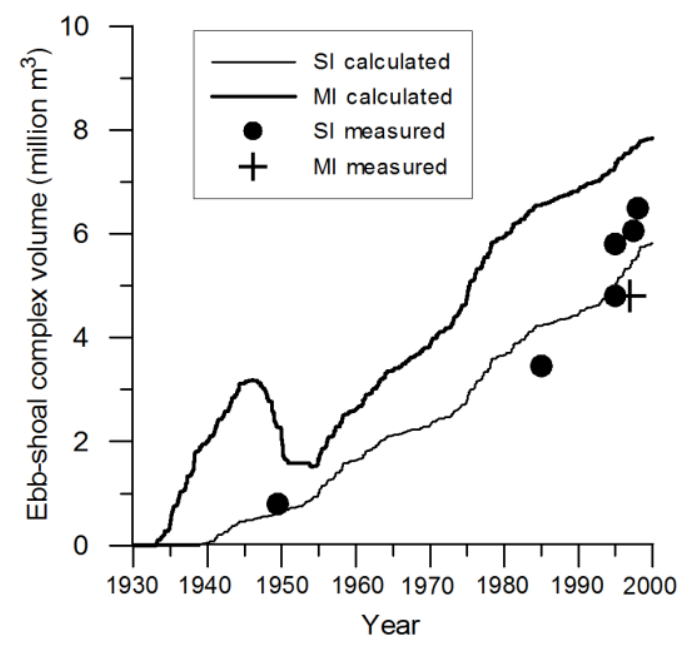

Figure 7. Comparison between the measured and calculated volume of ebb-shoal complex (SI = Shinnecock Inlet, $\mathrm{MI}=$ Moriches Inlet).

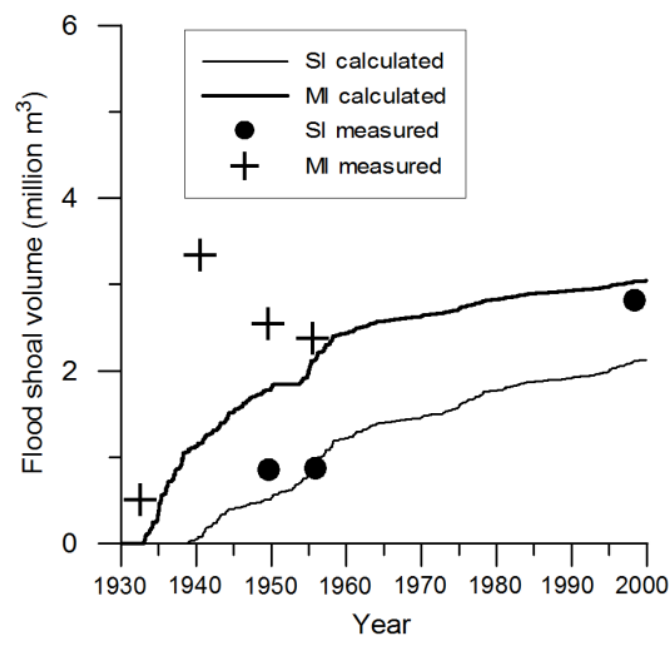

Figure 8. Comparison between the measured and calculated volume of flood shoal $(\mathrm{SI}=$ Shinnecock Inlet, $\mathrm{MI}=$ Moriches Inlet).

\section{CONCLUSIONS}

A new numerical model of regional sediment transport and shoreline change combined with the inlet reservoir model was developed and successfully applied to simulate the evolution of the south shore of the Long Island coast, New York. The model was employed to simulate the period from 1933 to 2000, which included inlet opening and closure. The simulations covered a stretch of coastline from Montauk Point to Fire Island Inlet that includes two tidal inlets and other complex conditions involving a wide range of structures and activities such as jetties, groins, and beach fill. Model calculations were compared with measured shoreline evolution, annual net longshore transport rates reported in the previous literatures, and measured flood shoal and ebb shoal complex volumes. The simulated shoreline agreed well with the measured shoreline, including the accumulation updrift the inlets, the overall erosion downdrift the inlets, and the formation of salient-type features downdrift the inlets. The annual net longshore transport rates were overall in good agreement with the reported data, showing an increase in transport rate going west from Montauk Point. The growth of the flood and ebb shoal complexes at the inlets was also well predicted. 
In order to realistically simulate the erosion and development of the salient-type feature downdrift the inlets, the predictive formula for the longshore transport rate was modified by introducing an attenuation coefficient for breaking wave height in the lee domain of the attachment bars. Also, sand bypassing from the bar to the shore was included in the inlet reservoir model. This modeling approach was indirectly validated through the improved agreement between the simulated and measured shoreline change downdrift of the inlet, in comparison with the previous model by Larson et al. (2002a), which failed to capture the details of the shoreline response downdrift the inlets.

The empirical formulas for calculating the distance from the centerline of an inlet to the attachment bars based on the tidal prism, developed by Carr and Kraus (2001), were modified by including the angle between ebb jet and the local shoreline trend. The average calculated distances from the inlet to updrift and downdrift attachment bars are, respectively, $250 \mathrm{~m}$ and $1150 \mathrm{~m}$ for Shinnecock Inlet, and $310 \mathrm{~m}$ and $1070 \mathrm{~m}$ for Moriches Inlet. These values are close to reported field data, implying that the updrift attachment bars are close to the jetties at both inlets, but the downdrift attachment bars extend to about $1200 \mathrm{~m}$ at Shinnecock Inlet (Williams et al., 1998) and approximately $1100 \mathrm{~m}$ at Moriches Inlet (Psuty et al., 2005). The calculated results show that the empirical formulas proposed, Eqs. (18) and (19), which include the angle between the ebb jet and the local shoreline, work reasonably well for the study site.

Application of the model to the Long Island coast shows the capability of the model to simulate regional sediment transport and shoreline evolution for complex conditions. Thus, a simulation domain may extend over hundreds of kilometers and cover several inlets including opening and/or closure, development of flood shoal and ebb shoal complexes, different shore protection measures, and shoreline response in the vicinity of inlets.

\section{ACKNOWLEDGMENTS}

This work was partly funded by the Swedish International Development Cooperation Agency (Sida/SAREC) in the framework of the Project VS/RDE/03 "The evolution and sustainable management in the coastal areas of Vietnam" (LXH and PTN), partly by Coastal Morphology Modeling and Management (Cascade) work unit, System-wide Water Resources Program conducted at the U.S. Army Engineer Research and Development Center (ML and $\mathrm{HH}$ ), and partly funded under the Regional Sediment Management Program and under the Inlet Geomorphologic Work Unit of the Coastal Inlets Research Program of the U.S. Army Engineer Research and Development Center (ML and HH). Support from Sida/SAREC project SWE-2007-123 is also appreciated. The travel expense to present these study results at the $32^{\text {nd }}$ International Conference on Coastal Engineering in Shanghai, China, was funded by Ångpanneföreningens Forskningsstiftelse (foundation). Permission was granted by Headquarters, U.S. Army Corps of Engineers, to publish this information.

\section{REFERENCES}

Bayram, A., Larson, M., and Hanson, H. (2007). A new formula for the total longshore sediment transport rate. Coastal Engineering, 54(2007), 700-710.

Carr, E.E. and Kraus, N.C. (2001). Morphologic Asymmetries at Entrances to Tidal Inlet. Coastal and Hydraulics Engineering technical Note IV-33, U.S. Army Engineer Research and Development Centre, Vicksburg, MS.

Dean, R.D. and Walton, T.L. (1975). Sediment transport processes in the vicinity of inlets with special reference to sand transport. Estuary Research, Volume II, Geology and Engineering, L.E. Cronin, ed., Academy Press, New York, 129-149.

FitzGerald, D.M.; Kraus, N.C. and Hands, E.B., (2000). Natural Mechanisms of Sediment Bypassing at tidal Inlets. Coastal and Hydraulics Engineering Technical Note ERDC/CHL CHETN-IV-30, U.S. Army Engineering Research and Development Centre, Vicksburg, MS.

Gaudiano, D.J. and Kana T.W., (2001). Shoal bypassing in mixed energy inlets: Geomorphic variables and empirical predictions for nine south Carolina Inlets. Journal of Coastal Research, 17(2), 280291.

Hanson, H., (1987). GENESIS: A generalized shoreline change numerical model for engineering use. Lund, Sweden: Department of Water Resources Engineering, Lund University, Ph.D. thesis, 206p.

Hanson, H., Larson, M., Kraus, N.C., and Gravens, M.B. (2006). Shoreline response to detached breakwaters and tidal current: Comparison of numerical and physical models. Proceeding of the $30^{\text {th }}$ Coastal Engineering Conference, World Scinetific, 3357-3369.

Hicks, D.M. and Hume, T.M. (1996). Morphology and size of ebb tidal deltas at natural inlets on opensea and pocked-bay coasts, North Island, New Zealand. Journal of Coastal Research, 12(1), 47-63. 
Jarrett, J.T., (1976). Tidal prism - inlet area relationships. U.S. Army Engineer Waterways Experiment Station, Vickburg, Mississipi, 60p.

Kana, T.W.; Hayter, E.J. and Work, P.A. (1999). Mesoscale sediment transport at southeastern U.S. tidal inlets: Conceptual model applicable to mixed energy settings. Journal of Coastal Research, 15(2), 303-313.

Kana, T.W.; Williams, M.L. and Stevens, D. (1985). Managing shoreline changes in the presence of nearshore shoal migration and attachment. Proceedings of Coastal Zone'85 (ASCE, New York), 1277-1294.

Kraus, N.C. (2000). Reservoir model of ebb-tidal shoal evolution and sand bypassing. Journal of Waterway, Port, Coastal, and Ocean Engineering, 126(3), 305-313.

Kraus, N.C. (2002). Reservoir model for calculating natural sand bypassing and change in volume of ebb-tidal shoals, part I: Description. Coastal and Hydraulics Engineering Technical Note ERDC/CHL CHETN-IV-39, U.S. Army Engineering Research and Development Centre, Vicksburg, MS.

Larson, M.; Kraus, N.C. and Connell, K.L. (2006). Modeling sediment storage and transfer for simulating regional coastal evolution. Proceeding of the $30^{\text {th }}$ Coastal Engineering Conference (California, USA), World Scientific, 3924-3936.

Larson, M.; Kraus, N.C. and Hanson, H. (2002a). Simulation of regional longshore sediment transport and coastal evolution- the Cascade model. Proceeding of the $28^{\text {th }}$ Coastal Engineering Conference. World Scientific Press, 2612-2624.

Larson, M.; Rosati, J.D. and Kraus, N.C. (2002b). Overview of regional coastal processes and controls. Coastal and Hydraulics Engineering Technical Note CHETN XIV-4, U.S. Army Engineer Research and Development Center, Vicksburg, MS.

Militello, A. and Kraus, N.C. (2001). Shinnecock Inlet, New York, site investigation, Report 4, Evaluation of flood and ebb shoal sediment source alternatives for the west of Shinnecock Interim Project, new York. Technical Report CHL-98-32, U.S. Army Corps of Engineers, Engineer Research and Development Centre, Vicksburg, MS.

Pelnard-Considere, R., (1956). Essai de theorie de l'evolution des forms de rivage en plage de sable et de galets. 4th Journees de l'Hydraulique, Les Energies de la mer, Question III, Rapport No. 1, pp. 289-298 (in French).

Psuty, N.P.; Grace, M. and Pace, J.P. (2005). The coastal geomorphology of Fire Island, A portrait of continuity and change. Technical Report NPS/NER/NRTR-2005/021. U.S. Department of the Interior, National Park Service, Northeast Region, Boston, Massachusetts.

Rosati, J.D.; Gravens, M.B. and Smith, W.G. (1999). Regional sediment budget for Fire Island to Montauk Point, New York, USA. Proceeding of Coastal Sediment'99, ASCE, 803-817.

Smith, W.G.; Watson, K.; Rahoy, D.; Rasmussen, C. and Headland, J.R. (1999). Historic geomorphology and dynamics of Fire Island, Moriches and Shinnecock Inlets, New York. Proceedings of Coastal Sediment'99, ASCE, 1597-1612.

Vogel, M.J. and Kana, T.W., (1984). Sedimentation patterns in a tidal inlet system, Moriches inlet, New York. Proceeding of the 19th Coastal Engineering Conference. World Scientific, 3017-3033.

Walton, T.L. and Adams, W.D. (1976). Capacity of inlet outer bars to store sand. Proceeding of Coastal Engineering-1976, 1919-1937.

Williams, G.L.; Morang, A. and Lillycrop, L. (1998). Shinnecock Inlet, New York, site investigation, Report 2, Evaluation of sand bypass options. Technical Report CHL-98-32, U.S. Army Corps of Engineers, Waterways Experiment Station, Vicksburg, MS.

Williams, M.L. and Kana, T.W. (1987). Inlet shoal attachment and erosion at Isle of Palms, South Carolina: A replay. Proceedings of Coastal Sediment'87, (Columbia, SC), 1174-1187. 